\section{European brain research}

SIR — We have read with great interest the recommendations of $F$. Gros, G. P. Tocchini-Valentini and their committee of molecular biologists on priorities for the support of scientific research and technological development by the European Union (Nature 369, 11-12; 1994). We approve totally of their suggestions on the provision of European infrastructures for data libraries and for stocks of genetically modified animals. The transnational mobility of young researchers (supported by the Human Capital and Mobility programme) and the new proposal to enable young scientists to form research groups outside their country of origin must surely enhance both the excellence of European research and the cohesion of the European community.

The research programme in molecular biology suggested by the committee will have an important impact on many areas of the life sciences. The European Molecular Biology Organisation already does an excellent job in promoting many of the aims of the proposed research. We were, therefore, surprised to find that research on the brain and cognition merits such a small place in the proposed programme. This attitude contrasts sadly with that in the United States, where the $1990 \mathrm{~s}$ are the "Decade of the Brain", and that in Japan, whose major contribution to the International Human Frontier Research Programme has enormously aided collaborative research in both neurobiology and molecular biology.

We feel that coordinated European support for specific studies on the brain in health and disease is crucial if we are not to fall behind our collaborators and competitors in the United States and Japan. Knowledge of brain function is the only way by which we can understand ourselves — how we perceive and respond to external events, how we think and how we remember. Novel physical, imaging techniques will provide important insights into these process. The effects of ageing, addiction, and neurological and psychiatric diseases are highly damaging to our society. Rational design of drugs to combat such disorders depends crucially on research that will allow the pharmaceutical industry to enhance the health of our citizens as well as the competitiveness of European industry. An increased understanding of the molecular, synaptic and network mechanisms by which the brain stores, retrieves and analyses information is important not only in itself but also to provide a basis for the design of the next generation of computing and robotics devices.

We hope that Commissioner Ruberti can find the means to support specific projects to foster excellence in European research and development in the neurosciences.

Jean-Plerre Changeux (Institut Pasteur, 28 rue du DrRoux, 75724 Paris Cedex 15 , France); P. Andersen (Oslo, Norway); M. J. Berridge (Cambridge, UK); C. Blakemore (Cambridge, UK); T. Bliss (London, UK); Alberto Ferrus Gamero (Madrid, Spain); T. Freund (Budapest, Hungary); R. Grantyn (München, Germany); S. Grillner (Stockholm, Sweden); K. Hepp (Zurich, Switzerland); T. Hökfelt (Stockholm, Sweden); J. Hounsgaard (Copenhagen, Denmark); H. Korn (Paris, France); R. Levi-Montalcini (Roma, Italy); R. Miles (Paris, France); J.-C. Schwartz (Paris, France); W. Singer (Frankfurt, Germany); P.Strata (Italy); E. S. Vizi (Budapest, Hungary); W. Wadman (Amsterdam, Netherlands); S. Zeki (London, UK)

\section{No hitch-hikers}

SIR - Bob Ward (Nature 368, 579; 1994) is right to raise the alarm about universities that insist on a supervisor's name being included on a paper irrespective of the supervisor's contribution, because this practice compromises the integrity of science. The reason for publishing is not to get brownie points for funding or notches on the $\mathrm{CV}$ gun, but to make new information public. The words 'author' and 'authority' have the same derivation and being an author means having the intellectual authority to defend the work and to take responsibility for it. That authority comes from being able to point to parts of a paper that exist only because of the author's efforts.

Claiming such authority without having it is fraudulent. For instance, part of the Statement on Scientific Practice issued by the Australian National Medical Health and Research Council, says: "Minimum requirement for authorship would be participation in conceiving and/or executing and/or interpreting at least part of the publication in a co-author's field of expertise, sufficient for him/her to take public responsibility for it. . . 'Honorary authorship' occurs when a person is listed as an author of a publication when he/she has not participated in a substantial way in conceiving and/or executing and/or interpreting at least part of the work described in the publication. 'Honorary authorship' is an unacceptable practice."

The only room for doubt in that statement lies in interpreting "substantial", but

Letters submitted for Correspondence should be typed, double-spaced, on one side of the paper only.
E. J. Huth's five principles of authorship (Ann. int. Med. 104, 269-274; 1986, summarized below) help to clarify this. (1) Each author should have participated sufficiently in the published work to take public responsibility for the content.

(2) Participation must include three steps: (i) conception or design of the work represented by the article, or analysis and interpretation of the data, or both; (ii) drafting the article or revising it for critically important content; and (iii) final approval of the version to be published. (3) Participation solely in the collection of data (or other evidence) does not justify authorship.

(4) Each part of the content of an article critical to its main conclusions and each step in the work that led to its publication (steps (i), (ii) and (iii) in Principle (2)) must be attributable to at least one author. (5) People who have contributed intellectually to the article but whose contributions do not justify authorship may be named and their contribution described for example, 'advice', 'critical review of study proposal', 'data collection', 'participation in clinical trial'.

\section{Robert Brown}

Agricultural Production Group,

Queensland Department

of Primary Industries,

GPO Box 46, Brisbane,

Australia 4001

\section{Many thanks}

SIR - Science in the former Soviet Union depends and will continue to depend on the availability of information. Until 1991, there was a well developed infrastructure of libraries and express information services. But this system has almost collapsed because of the shortage of international journals and books due to the lack of hard currency.

In this situation, the help we are receiving from elsewhere is of paramount importance. Mr George Soros has done much to support libraries in the former Soviet Union, as has the German government. Scientific organizations in the United States, France and other countries are also sending us publications. We are particularly grateful for the generous response of scientists to requests for reprints. Provincial libraries and universities are even worse affected than those in Moscow, so reprints are often our only source of information.

It is not possible to write to all those who have helped and are helping us, but I should like to assure them that we read, analyse and cite their papers.

A. R. Kacimov

Kazan University,

17 University Street,

Kazan 420008, Tatarstan, Russia 